(2) OPEN ACCESS

Social and Behavioral Sciences, University of California San Francisco, San Francisco, California, USA

Correspondence to Dr Elizabeth A Smith, Social and Behavioral Sciences, University of California San Francisco, San Francisco, CA 94143, USA; libby.smith@ucsf.edu

Received 27 March 2019 Revised 21 August 2019 Accepted 26 August 2019 Published Online First 21 September 2019
Check for updates

(C) Author(s) (or their employer(s)) 2020. Re-use permitted under CC BY-NC. No commercial re-use. See rights and permissions. Published by BMJ.

To cite: Smith EA, Malone RE. Tob Control 2020;29:703-708.

\title{
An argument for phasing out sales of cigarettes
}

\author{
Elizabeth A Smith ๑ , Ruth E Malone
}

\section{ABSTRACT}

The successes of tobacco control in some countries and locales have led to discussions of ending the tobacco epidemic, often called the 'endgame'. In this paper, we recommend articulating the endgame goal as phasing out sales of cigarettes, a goal once called 'unthinkable'. We develop a logic and argumentation for ending cigarette sales intended to move the discussion beyond the shadow of 'prohibition', proposing an approach that appeals to consumer protection standards and suggesting that the effort be led by low-prevalence communities. While phasing out cigarettes will not happen everywhere all at once, and may unfold differently along several lines, we argue that the gradual phase-out approach we propose will reduce the likelihood of the negative consequences often predicted to come with such a policy. To continue permitting widespread sales of the single most deadly consumer product in history is a public health failure that must be addressed.

The idea of developing an 'endgame' plan for tobacco has engaged researchers and public health advocates for the last decade. ${ }^{1-4}$ Several countries have set endgame goals. ${ }^{5-9}$ Endgame framing has encouraged advocates to move beyond an ongoing struggle to 'control' tobacco's impacts to imagine that an endpoint - a specific, measurable outcome marking an end to the tobacco epidemic -- is possible in the foreseeable future, and to begin to develop strategies to achieve it. ${ }^{2-41011}$

Although the 'endgame' term is used widely, its definition remains ambiguous. There is little consensus on whether new policies are needed, beyond full, effective implementation of the measures called for by the World Health Organization Framework Convention on Tobacco Control. ${ }^{12}$ There is also variability in the goals countries have set. For example, Finland has asserted a goal of less than $5 \%$ daily tobacco use prevalence by $2030 .^{6} 13$ Canadians recently discussed an endgame goal of 'less than 5 (\% prevalence) by 2035'.5 Denmark's goal is: 'none of the children born today smoking in 2030'.

It is unsurprising that there is some scepticism regarding the tobacco endgame. Most innovative tobacco control policies were initially regarded as impractical, impossible or extreme before eventually becoming standard features of the policy landscape. Furthermore, everyone working in tobacco control today was born in the 'cigarette century"14; thus, no one now alive has experienced a time when commercial tobacco products were not ubiquitously sold (except perhaps recently in Bhutan, which banned tobacco sales and production)..$^{15}$ These circumstances make imagining an endgame especially challenging. In this paper, we argue that ending cigarette sales, led by jurisdictions with already-low smoking prevalence, should be articulated publicly as the endpoint goal. Ending sales of cigarettes, widely acknowledged to be the most deadly consumer product on the market, would advance public health by treating them like many other (unsafe) products.

As a global oligopoly, the tobacco industry has enough money to influence policy-makers, outspend political opponents, and create social, political and scientific institutions to act on its behalf. These activities have created the current situation, in which jurisdictions struggle to conceptualise a workable policy regime to end the tobacco epidemic. The fact that even tobacco control advocates, who understand the devastation tobacco has caused, often dismiss the idea of ending cigarette sales as naïve, infeasible or unwise, suggests how deeply normalised cigarette sales still remain. While we do not underestimate the magnitude of the effort required to end cigarette sales on a large scale, unwillingness to name it as a goal renders it impossible to achieve.

We define the endpoint as ending sales of cigarettes and similar combusted products (eg, little cigars), because in most countries, they are responsible for the largest part of tobacco-caused morbidity and mortality. They also remain the tobacco industry's single largest source of profits and power. The place in the endgame of other, apparently less hazardous products (such as lownitrosamine smokeless tobacco products, heated tobacco products and e-cigarettes), may vary by jurisdiction, as we discuss below. Here, we discuss the evidence suggesting that ending cigarette sales will be an effective endgame approach, and propose a logic and argumentation for phasing out cigarette sales that moves beyond the 'prohibition doesn't work' narrative trope.

\section{EVIDENCE FOR PHASING OUT CIGARETTE SALES}

Although the outcome of new policies is always uncertain, evidence suggests that removing cigarettes from the market would result in fewer people smoking. Higher tobacco outlet density is associated with a higher likelihood of smoking initiation by minors ${ }^{16}$ and adults, ${ }^{17}$ and living near tobacco outlets is associated with unsuccessful quit attempts. $^{18}{ }^{19}$ Emerging evidence also suggests that tobacco retailer reduction is associated with a decline in cigarette pack purchases. ${ }^{20}$ In the USA, point of sale promotions are the most visible tobacco advertisements; eliminating such promotions (as would occur if sales were ended) is also associated with reduced odds of regular smoking among adults ${ }^{21}$ and adolescents. ${ }^{22}$ Ending cigarette sales would also have a powerful secondary impact: 
further denormalising the cigarette industry. Tobacco industry denormalisation is associated with reduced smoking prevalence among youth and young adults, reduced smoking initiation among youth, and increased intentions to quit. ${ }^{23}$

\section{THE ENDGAME AND CONSUMER PRODUCT SAFETY}

The idea of abolishing cigarette sales frequently raises concerns (at least in the US context) about alcohol prohibition and the various problems that accompanied it. ${ }^{24}$ But prohibition is not the only historical and rhetorical parallel; other laws and norms can be drawn on to shape understanding of ending cigarette sales. In 1985, the United Nations unanimously adopted guidelines for consumer protection. The guideline on physical safety states that 'Governments should adopt or encourage the adoption of appropriate measures... to ensure that products are safe for either intended or normally foreseeable use. ${ }^{25}$ Beyond these guidelines, in the 20th century, many countries developed more specific laws and regulations aimed at protecting the public. In the countries with the largest multinational tobacco companies (ie, the USA, the UK, Japan and the European Union nations), it is now taken for granted that cars undergo crash tests before they are sold, food manufacturers and processors are held to hygienic standards, and drugs undergo clinical trials to establish safety and effectiveness. Legal consumer products found to be hazardous are regularly pulled from the market, such as toys presenting choking hazards for children; batches of contaminated processed food or individual components of complex goods (eg, batteries, airbags) that work improperly. Manufacturers or retailers sometimes recall goods that appear to malfunction, even without reported injuries. For the most part, consumers assume that products offered for sale are reasonably safe.

Additionally, tobacco control practitioners are using human rights standards. The 2018 Cape Town Declaration on Human Rights and a Tobacco-free World finds that 'the manufacture, marketing and sale of tobacco are incompatible with the human right to health', and reaffirms the International Covenant on Economic, Social and Cultural Rights (ICESCR) statement that the 'failure to discourage production, marketing and consumption of tobacco' is a 'violation of the obligation to protect' the right to health. ${ }^{26} 27$

The bizarre exception to both standards is the cigarette, shown to kill as many as two-thirds of its long-time users ${ }^{29}$ yet essentially unregulated. (The regulations in place largely apply to packaging, promotion or sales, not the design or contents of the product itself.) When consumer protection agencies and laws were established, in the early $20^{\text {th }}$ century, tobacco was omitted. The cigarette continued to be sold even as evidence about its dangers mounted, due to the industry's political power. ${ }^{14} 30$ The US Food and Drug Administration (FDA), for example, had no power to regulate tobacco until recently, as tobacco was excluded from its jurisdiction as not 'intended to affect the structure or any function of the body' (the definition of a drug). ${ }^{31}$ (In fact, the tobacco industry intentionally engineered its products in multiple ways to maximise certain effects on the body, but this was not widely known. ${ }^{32}$ ) Even now, a decade after the 2009 US Family Smoking Prevention and Tobacco Control Act (FSPTCA) which gave the FDA regulatory power over tobacco products, the FDA has no power to remove these existing, 'grandfathered' deadly products from the market, ${ }^{33}$ so no national phase-out of cigarette sales would be possible in the USA without Congressional action, a highly unlikely scenario. However, as we discuss below, other options are possible, and for various reasons, probably preferable.

\section{THE 'RIGHT' TO USE VERSUS THE 'RIGHT' TO SELL}

The tobacco industry defines the central issue of tobacco control as the individual right to use tobacco, ${ }^{34} 35$ eliding the issue of a company's responsibility to sell safe products. This framing has been successful: attempts to discuss removing cigarettes from the market frequently give rise to questions not about the ethics of allowing them to be sold, but about the ethics of restricting consumer freedom, ${ }^{36}$ the assertions of the Cape Town Declaration and ICESCR notwithstanding. However, in the USA, at least, it is clear that there is no legal 'right to smoke'. ${ }^{37}$

From the consumer protection standpoint, most people do not believe that people 'need', 'deserve' or 'have the right to' purchase cars that are unsafe to drive, medications that poison them or food that spreads disease. The promulgation of the idea that there is a 'right' to buy cigarettes, and the characterisation of the industry as a simple conduit of those products, an inevitability of a naturally occurring market, are arguably the most potent, deceptive and dangerous aspects of tobacco industry power. The 'right to smoke' framing obscures the generally accepted ethical obligation of reputable companies to sell only products that do not cause great harm when used as intended.

To plan an end to cigarette sales, therefore, requires comprehending and developing strategies for conveying to the public that the cigarette industry is an extreme outlier in the legal and regulatory landscape of consumer protection, rather than an ordinary business. In terms of consumer protection, the goal is to create a level playing field, in which the tobacco industry must meet normal expectations for product safety. With a consumer protection framing, rational policy-making follows: laws and norms that ensure the safety of consumer products should apply to cigarettes. Tobacco control policy could be truly guided by the principles of Cape Town, ICESCR, and the UN guidelines.

In the USA, tobacco products are exempted from the Consumer Products Safety $\mathrm{Act}^{38}$; however, the Act does not prevent states and other jurisdictions from enacting more stringent standards than those established by the Act, and they often do. Similarly, the 2009 FSPTCA specifically permits state or local jurisdictions to adopt more stringent laws 'relating to or prohibiting the sale, distribution, possession, exposure to, access to, advertising and promotion of, or use of tobacco products by individuals of any age, ${ }^{33}$ leaving the door open for states or local governments to end cigarette sales. The 50th Anniversary edition of the US Surgeon General's Report on the Health Consequences of Smoking explicitly proposes state or local bans on sales of whole classes of tobacco products. ${ }^{39}$

\section{BENEFITS OF ENDING SALES}

Ending sales deprives the industry of income and represents the most concrete way to denormalise the product. Equally importantly, ending sales could reduce the industry's influence in government and policy-making by challenging its legitimacy. ${ }^{40}$ Notably, however, defining the endpoint as ending cigarette sales does not require that no one could or would ever use tobacco (or other nicotine products). Tobacco is a product that has been used in some form for centuries and some use (both ritual and addiction based) is likely to continue; however, it is only since the commercialisation of cigarettes that the problems its use causes have reached epidemic proportions. ${ }^{14} 32$ Not expecting policies to achieve total 'prohibition' or zero prevalence recognises this.

Objectors to proposed endgame-advancing policy proposals commonly refer to black markets or the failures and unintended consequences of alcohol prohibition. But these objections, often supported by industry-funded research, typically 
assume exaggerated proportions of illicit trade. ${ }^{41}$ Furthermore, under Prohibition, alcohol use prevalence was high, many users perceived their own use to be unproblematic, and possession and use were criminalised, leading to widespread law-breaking and reduced respect for law enforcement. In contrast, phasing out cigarette sales in a jurisdiction with already-low smoking prevalence (without reference to possession and use) is quite different. Many smokers already perceive their own use to be problematic (eg, they want to quit ${ }^{42}$ ) and thus might be less likely to seek out illicitly sold cigarettes. Furthermore, eliminating ready access to cigarettes could enhance success in cessation, since smokers experience stronger cravings when they expect to be able to smoke in the near future. ${ }^{43} 44$ While some illegal underground sales (whether home-grown or through neighbouring communities) are likely to occur, these types of activities seem unlikely to represent a black market so substantial that it would become worse for public health than the status quo.

To make phasing out cigarette sales the endpoint goal, it is not necessary to envision it as happening everywhere all at once. Rather, we predict that ending cigarette sales will take place gradually, jurisdiction by jurisdiction, beginning in low-prevalence locales and potentially supported by a new narrative about fairness under consumer protection principles. This is particularly true in the USA, where many cities and counties have the ability to enact innovative laws. This gradual implementation of sales bans city by city, rather than being a problem, could make genuinely substantial black markets less likely to flourish. The combination of a relatively small customer base (due to already-low prevalence in the jurisdictions initiating the policies) and the modest initial extension of distance for consumers to purchase legally would render the risks involved in a highly organised black market operation less attractive.

The history of US tobacco control policy suggests that each location taking this step may enable others to do likewise, and that new policies can change the prevailing narrative about tobacco. For example, Beverly Hills, California is ending sales of cigarettes and other products as of January 2021. ${ }^{45}$ Beverly Hills has a population of approximately 34000 with a low smoking prevalence, and is surrounded by the much larger city of Los Angeles. Assuming it implements the ordinance, cigarettes will still be available in adjacent areas. However, other jurisdictions in the region are already studying this option. If the policy spreads (as, for example, clean indoor air laws did, despite industry efforts) an eventual statewide policy ending cigarette sales would have a significant impact on smoking, and also on the industry and its political influence in the state.

\section{FEDERAL ACTION}

There are some indications that the FDA could at some point move to implement a product standard for all cigarettes sold in the USA that would mandate lowering nicotine to minimally or nonaddictive levels. ${ }^{46}$ Given the extensive time involved in federal rulemaking, it is difficult to predict whether and when such a strategy will be operationalised. However, the very low nicotine content (VLNC) cigarette requirement could actually work in tandem with a gradually executed phase-out of cigarette sales as a complementary strategy, rendering it less likely that consumers would make the additional effort to travel to neighbouring jurisdictions to obtain the less-attractive and less-addictive VLNC cigarettes still being sold there. While a black market in higher nicotine cigarettes is possible, that would be a possibility of the VLNC strategy itself, not a direct consequence of ending cigarette sales in a community with already-low prevalence.

\section{CHANGING THE NARRATIVE}

Achieving an end to the tobacco epidemic will be an arduous and lengthy process. But advocates must be willing to state publicly their goal. For any endgame plan, the narrative about cigarette sales must shift to end the perception that cigarettes are an ordinary consumer product. Rather, selling cigarettes should be characterised as selling an inherently defective/unsafe product that falls into the same category as contaminated food, asbestos and lead paint. These are products that states find too hazardous to be made available to the public, and regardless of cost (lost tax revenue/increased regulation/jobs eliminated), the government removes them from the marketplace.

Tobacco control advocates may believe that they have already been giving the clear message that cigarettes are too hazardous to use, but by tacitly acceding to the idea that cigarette sales must continue, that message is continually undermined. The confusion this causes is expressed by smokers who ask: if cigarettes are so dangerous, why are they legally and widely available for sale? Some also question whether raising tobacco taxes is less about public health and more for the benefit of the state's bottom line, at the expense of smokers. Tobacco control advocates have contributed to this perception by advancing tobacco taxes as beneficial for state economies, beyond the reductions in consumption they produce. These lines of argument can give tobacco control proponents a credibility problem that industry apologists exploit.

\section{CHALLENGES \\ Industry opposition}

Achieving an end to cigarettes sales will require: low tobacco use prevalence rates (particularly in early adopting jurisdictions); an awareness among the public that the current situation is legally anomalous and ethically unacceptable; policy-makers prepared to act to protect public health despite industry opposition, loss of tobacco industry campaign contributions and lost tax revenues from cigarettes; and policy measures that are consistent with those values. Additional strategic legal, constitutional, ethical, historical, political and communications research will be needed to advocate for an end to cigarette sales in various jurisdictions while continuing to implement 'status quo' tobacco control measures. The consumer products safety narrative we discuss is just one approach to building the case; in different places, different narratives (eg, human rights and social justice) may be more effective or resonant with existing law and social norms.

However, it is important to note that the tobacco industry no longer exerts the social and political power it once did, particularly in the many locales discussing endgame ideas. Indicators include a recent move towards divestment from tobacco stocks from large portfolios ${ }^{47-50}$; refusal of journals to publish tobacco industry funded research ${ }^{5152}$; refusal of policy-makers to accept campaign contributions from tobacco companies and failure of tobacco industry-sponsored ballot initiatives. ${ }^{53}$

\section{Public opposition}

Up to $90 \%$ of smokers regret that they started ${ }^{54}$ and $70 \%$ want to quit ${ }^{42}$; thus in the areas with low smoking prevalence $(<10 \%)$ likeliest to implement cigarette sales bans under our proposal, the total population who would potentially object strongly would be about 1\%-3\% (ie, the 10\%-30\% of smokers who do not regret starting and/or do not want to quit). Polling data from various regions and countries indicate that, even in the absence 
of any campaigns for ending cigarette sales, majorities of nonsmokers (and 12\%-46\% of smokers) support the idea. ${ }^{3}$

\section{Gradual versus abrupt approaches}

Normally, once a product is determined to be unsafe, sales are stopped as quickly as possible. However, a phased approach to ending cigarette sales seems more practicable from both political and consumer perspectives. One historical parallel is leaded gasoline. As with tobacco, manufacturers knew for decades that leaded gasoline was hazardous and concealed that knowledge. ${ }^{55}$ Still, the eventual phase-out of leaded gasoline in the USA took a decade. ${ }^{56}$

A gradual approach acknowledges the difficulties associated with eliminating a widely used and addictive product. However, those difficulties should not be overstated. Notwithstanding the popular idea that tobacco is more addictive than heroin, ${ }^{57}$ compared with some other addictive substances, withdrawal from nicotine is mild. The legality, ubiquity and cheapness of cigarettes, as well as the lack of immediate visible negative consequences to smoking, make them 'more difficult to quit than heroin', not their neurochemical effects or the severity of withdrawal. In places where tobacco control is more advanced a 'softening' of the remaining smoking population has occurred, rather than the 'hardening' theorised by some proponents of market-based approaches to the endgame. ${ }^{58}$ This means that the remaining smokers, while they may find quitting difficult, are less invested in continuing to smoke. Given that $70 \%$ of smokers say they want to quit, ${ }^{42}$ reducing product availability and accessibility can support smokers by reducing relapse. ${ }^{43} 44$ Policy adoption rarely happens quickly, and the debate over ending sales would give smokers motivation to prepare by quitting. Nicotine replacement products (both pharmaceutical and commercial) are readily available. In many places, e-cigarettes or other alternative products would also remain available. Therefore, it would potentially be feasible for jurisdictions to adopt policies with a short phase-out period.

The envisioned jurisdiction-by-jurisdiction approach is in itself a gradual one. If cities or counties adopt sales bans, as in the Beverly Hills case, it is likely that acquiring cigarettes will initially only necessitate travel to nearby areas, becoming inconvenient rather than impossible. While some might interpret such measures as merely 'symbolic', virtually every important advance in tobacco control policy began with measures similarly characterised. For example, the initial efforts to achieve smoke-free sections in restaurants were, for all practical purposes, merely symbolic, since smoke still drifted from the smoking section. However, by establishing a different narrative understanding about the boundaries and effects of secondhand smoke, those early policies led the transition from symbolic to material.

\section{Substitute sources of revenue}

Another 'addiction' to address is that of the tobacco industry and states to tobacco revenue (profits or taxes) ${ }^{59}$ and the political power that sustains. Some jobs, particularly those involved in manufacturing, will be lost as cigarette sales decline. However, others may be created or changed. In places with already-low smoking prevalence, retailers will need to transition their business models in any case, as tobacco sales drop. Retailers, perhaps with incentives from governments, will find other products to sell.

Ending sales will mean weaning states from tobacco tax revenue. A moral argument can be made that necessities such as roads and schools should not be dependent on revenue from sales of lethal products. However, advocates and policy-makers will need to plan for sources of replacement revenue, planning that is needed anyway as smoking prevalence drops. In the long run, reduced healthcare costs will offset some revenue losses; in the short run, some financing structures will have to be reconsidered. It is important to note, however, that the money currently spent on cigarettes will not disappear when they are no longer sold: it will largely be spent on other taxed products. ${ }^{60}$

\section{Substitute products}

Cigarettes are sometimes considered unlike leaded gasoline or asbestos, because acceptable substitutes for those products were available when they were removed from the market. Currently, with the development of e-cigarettes and other tobacco and nicotine products, there are more substitutes for smoked tobacco than ever. Cigarettes are unlike leaded gasoline and asbestos, in that they have no useful cigarette-specific function to be replaced. The functions that cigarettes are advertised or sometimes claimed by smokers to provide (eg, relaxing, focusing and aiding in socialising) are not only desirable to smokers. It seems likely that, in the long run, the functions of cigarettes will be replaced with other products and practices now used by nonsmokers, with entirely new products, or, perhaps, with other tobacco or nicotine products with a lower harm profile. The nature of an 'acceptable substitute' also changes depending on whether the product being substituted is still readily available. Thus, those who currently choose cigarettes over other nicotine products will likely find other products more 'acceptable' once cigarettes are not as widely sold.

\section{Eliminating versus transforming the cigarette industry}

Some argue that endgame policies should focus on 'transforming' the industry through measures to encourage development, marketing and use of the proliferating variety of alternative nicotine devices instead of cigarettes, a narrative the industry is eager to further. ${ }^{61}$ Because the standard being set revolves around consumer product safety, regulators could set product safety standards and those meeting the standard could be sold where sales of such types of products were permitted. ${ }^{62}$ Currently, whether and which new products are in fact safe or safer long-term remains undetermined, though there are other existing tobacco and nicotine products currently on the market that research shows have lower harm profiles than cigarettes. ${ }^{6364}$ One important chapter from the history of tobacco control, the introduction of filtered and 'low-tar' cigarettes, shows that even products that intuitively seem safer, and even with research evidence demonstrating, for example, reduced toxicant yieldmay in fact prove otherwise as actually used. Although it has always been in the power of tobacco companies to transform themselves by ceasing to sell cigarettes (as they have promised to do if they were proven hazardous), ${ }^{6566}$ they continue to sell them. ${ }^{67}$ Public health policies that place cigarettes under the same consumer safety regimen as other products are efforts to 'transform the industry'.

This 'transformation' might mean that some cigarette companies are eventually forced out of business, if they cannot develop safe or markedly safer products. Recent actions addressing the bail bonds industry by two US states show that it is possible to enact policies that largely eliminate a thriving industry because it harms individuals and communities. New Jersey $(\mathrm{NJ})^{68}$ and, most recently, California, ${ }^{69}$ have largely eliminated cash bail, seeing it as unfair and harmful to people who cannot afford to pay it and thus may lose jobs, housing, or custody of children 
while presumed innocent and awaiting trial. An Atlantic City (NJ) editorial noted: 'Nationwide, bail bonding in 2016 was a US\$2 billion industry ... Much of that business is destined to disappear, along with many of the businesses and jobs. That's unfortunate, but pales compared with the harm to society from a system in which two-thirds of American prisoners have not even been convicted. ${ }^{68}$ Similar sentiments could apply to the eventual shuttering of cigarette companies.

\section{CONCLUSION}

Our analysis has primarily focused on the US context and the narrative framing of consumer products safety to make the case for phasing out cigarette sales. However, the move to end cigarette sales may unfold differently in other countries depending on their governmental structures, implementation and enforcement mechanisms, cultural contexts, and engagement with various versions of harm reduction. We have argued that a gradual, jurisdiction-by-jurisdiction phase-out of cigarette sales, beginning with low-prevalence jurisdictions, is justified based on consumer product safety standards, that it would be effective in denormalising the product, reducing tobacco use and relapse among smokers trying to quit, and that the potential negative consequences of such measures are mitigable or unlikely to be worse for public health than the current status quo.

The situation in low-income and middle-income countries, where tobacco companies are still aggressively seeking to build markets, may call for consideration of different approaches depending on the political and policy climate. However, being able to say to policymakers in those countries that many cities in wealthier countries have now ended sales of these products could provide important leverage for advocates. As some tobacco companies have themselves begun to discuss phasing out cigarette sales (in favour of other tobacco or nicotine products they produce), cities or countries ending sales could call the industry's bluff on cigarettes now, before smoking becomes more widespread.

Developing an endgame requires rethinking common assumptions about what is possible, and this has gradually changed over time. The tobacco industry and its allies have for years accused tobacco control of being 'prohibitionists' and 'health Nazis' for promoting such 'radical' ideas as clean indoor air. Advocates have often responded by denying these accusations, implicitly conceding a 'right to smoke' that ends only where it impinges on the health of non-smokers, and tacitly accepting the sale of deadly products. But a different approach is needed now.

Tobacco control suggests that tobacco will always be with us, and this might be true, since it is a naturally occurring plant in some areas. But the cigarette epidemic need not always be with

\section{What this paper adds}

- While discussions of an "endgame" for the tobacco epidemic have been ongoing for the past decade, the cigarette- the single most deadly consumer product in history-remains widely available for sale. This represents a massive public health failure to protect.

- This paper, drawing on principles of consumer protection, makes the argument that phasing out sales of cigarettes should be the endgame goal, led first by low-prevalence jurisdictions with strong tobacco control policies. We offer evidence that such an approach would be likely to further reduce smoking and have minimal negative unintended consequences. us. That is a product of the $20^{\text {th }}$ century. Tobacco use on an individual level is perpetuated by addiction, but addiction and relapse are facilitated by widespread availability.

The tobacco endgame is all about understanding that it is time to stop devoting resources to addressing the industrially produced effects of the tobacco epidemic without directly addressing the cause: widespread sales of cigarettes. It is about applying the principles of consumer protection and human rights in a fair and equitable way to halt the sale of a deadly product. While the work to accomplish this will be daunting, it is not impossible, nor is it any longer so 'unthinkable, ${ }^{70}$ and it is worth doing. The cigarette century ${ }^{14}$ is over.

Acknowledgements The authors would like to thank Patricia McDaniel and the many reviewers of earlier versions of this paper for their valuable comments.

Contributors EAS wrote a first draft of the paper. REM and EAS both contributed to subsequent drafts.

Funding The authors have not declared a specific grant for this research from any funding agency in the public, commercial or not-for-profit sectors.

Competing interests REM owns one share each of Philip Morris International, Reynolds American and Altria stock for research and advocacy purposes and has participated in tobacco control advocacy. See full statement on funding here: https:// tobaccocontrol.bmj.com/pages/wp-content/uploads/sites/49/2016/12/RuthMaloneCo mpetinginterestsstatement.pdf

\section{Patient consent for publication Not required.}

Provenance and peer review Not commissioned; externally peer reviewed.

Supplemental material This content has been supplied by the author(s). It has not been vetted by BMJ Publishing Group Limited (BMJ) and may not have been peer-reviewed. Any opinions or recommendations discussed are solely those of the author(s) and are not endorsed by BMJ. BMJ disclaims all liability and responsibility arising from any reliance placed on the content. Where the content includes any translated material, BMJ does not warrant the accuracy and reliability of the translations (including but not limited to local regulations, clinical guidelines, terminology, drug names and drug dosages), and is not responsible for any error and/or omissions arising from translation and adaptation or otherwise.

Open access This is an open access article distributed in accordance with the Creative Commons Attribution Non Commercial (CC BY-NC 4.0) license, which permits others to distribute, remix, adapt, build upon this work non-commercially, and license their derivative works on different terms, provided the original work is properly cited, appropriate credit is given, any changes made indicated, and the use is non-commercial. See: http://creativecommons.org/licenses/by-nc/4.0/.

\section{ORCID iDs}

Elizabeth A Smith http://orcid.org/0000-0002-4712-513X

Ruth E Malone http://orcid.org/0000-0002-3324-2183

\section{REFERENCES}

1 Malone RE. Imagining things otherwise: new endgame ideas for tobacco control. Tob Control 2010;19:349-50.

2 Thomson G, Wilson N, Blakely T, et al. Ending appreciable tobacco use in a nation: using a sinking lid on supply. Tob Control 2010;19:431-5.

3 McDaniel PA, Smith EA, Malone RE. The tobacco endgame: a qualitative review and synthesis. Tob Control 2016;25:594-604.

4 van der Deen FS, Wilson N, Cleghorn $\mathrm{CL}$, et al. Impact of five tobacco endgame strategies on future smoking prevalence, population health and health system costs: two modelling studies to inform the tobacco endgame. Tob Control 2018;27:278-86

5 Health Canada. Government of Canada launches public consultation on the future of tobacco control in Canada, 2017. Available: https://www.canada.ca/en/healthcanada/news/2017/02/government_of_canadalaunchespublicconsultationsonthefu tureoftoba.html? wbdisable=true [Accessed $10 \mathrm{Apr}$ 2018].

6 Tobacco-free Finland 2030. Together towards a tobacco-free future, 2018. Available: https://savutonsuomi.fi/en/ [Accessed $10 \mathrm{Apr}$ 2018].

7 Department of Health (Ireland). Tobacco free Ireland, 2013. Available: http://static. rasset.ie/documents/news/tobacco-free-ireland.pdf [Accessed 10 Apr 2018].

8 Healthier Scotland: Scottish Government. Creating a tobacco-free generation: a tobacco control strategy for Scotland, 2013. Available: http://www.gov.scot/resource/ 0041/00417331.pdf [Accessed 10 Apr 2018].

9 RT News. Tata, tobacco! Denmark aims for 1st smoke-free generation by 2030, 2016. Available: https://www.rt.com/news/357209-denmark-smoke-free-generation/ [Accessed 10 Apr 2018]. 
10 Pearson AL, van der Deen FS, Wilson N, et al. Theoretical impacts of a range of major tobacco retail outlet reduction interventions: modelling results in a country with a smoke-free nation goal. Tob Control 2015;24:e32-8.

11 Smith TT, Hatsukami DK, Benowitz NL, et al. Whether to push or pull? Nicotine reduction and non-combusted alternatives - Two strategies for reducing smoking and improving public health. Prev Med 2018;117:8-14.

12 World Health Organization. WHO report on the global tobacco epidemic, 2008: the MPOWER package. Geneva, 2008

13 Levy DT, Blackman K, Currie LM, et al. SimSmokeFinn: how far can tobacco control policies move Finland toward tobacco-free 2040 goals? Scand J Public Health 2012:40:544-52.

14 Brandt AM. The cigarette century: the rise, fall, and deadly persistence of the product that defined America. New York: Basic Books, 2007.

15 Ugen S. Bhutan: the world's most advanced tobacco control nation? Tob Control 2003; 12:431-3

16 Schleicher NC, Johnson TO, Fortmann SP, et al. Tobacco outlet density near home and school: associations with smoking and norms among US teens. Prev Med 2016:91:287-93.

17 Cantrell J, Pearson JL, Anesetti-Rothermel A, et al. Tobacco retail outlet density and young adult tobacco initiation. Nicotine Tob Res 2016;18:130-7.

18 Chaiton MO, Mecredy G, Cohen J. Tobacco retail availability and risk of relapse among smokers who make a quit attempt: a population-based cohort study. Tob Control 2018;27:163-9.

19 Halonen Jl, Kivimäki M, Kouvonen A, et al. Proximity to a tobacco store and smoking cessation: a cohort study. Tob Control 2014;23:146-51

20 Polinski JM, Howell B, Gagnon MA, et al. Impact of CVS pharmacy's discontinuance of tobacco sales on cigarette purchasing (2012-2014). Am J Public Health 2017; 107:556-62.

21 He Y, Shang C, Huang J, et al. Global evidence on the effect of point-of-sale display bans on smoking prevalence. Tob Control 2018;27:e98-104.

22 Van Hurck MM, Nuyts PAW, Monshouwer K, et al. Impact of removing point-of-sale tobacco displays on smoking behaviour among adolescents in Europe: a quasiexperimental study. Tob Control 2019;28:401-408.

23 Malone RE, Grundy Q, Bero LA. Tobacco industry denormalisation as a tobacco control intervention: a review. Tob Control 2012:21:162-70.

24 Okrent D. Last call: the rise and fall of Prohibition. New York: Scribner, 2010.

25 United Nations Conference on Trade and Development. United Nations guidelines on consumer protection, 2015. Available: https://unctad.org/en/Pages/DITC/CompetitionLaw/ UN-Guidelines-on-Consumer-Protection.aspx [Accessed 26 Nov 2018].

26 United Nations Committee on Economic, Social and Cultural Rights. General comment no. 14: The Right to the Highest Attainable Standard of Health (Art. 12), 2000. Available: https:// digitallibrary.un.org/record/425041 [Accessed 27 August, 2019].

27 World Conference on Tobacco OR Health. Cape Town Declaration on human rights and a tobacco-free world, 2018. Available: https://ash.org/declaration/ [Accessed 8 Jan 2019].

28 Pirie K, Peto R, Reeves GK, et al. The 21st century hazards of smoking and benefits of stopping: a prospective study of one million women in the UK. Lancet 2013:381:133-41

29 Banks E, Joshy G, Weber MF, et al. Tobacco smoking and all-cause mortality in a large Australian cohort study: findings from a mature epidemic with current low smoking prevalence. BMC Med 2015;13:38

30 Kluger R. Ashes to ashes: America's hundred-year cigarette war, the public health, and the unabashed triumph of Philip Morris. New York: Knopf 1996.

31 Kessler D. A Question of Intent: A Great American Battle with a Deadly Industry. New York: PublicAffairs, 2001

32 Proctor RN. Golden Holocaust: Origins of the cigarette catastrophe and the case for abolition. Berkeley, CA: University of California, 2012.

33 Public Law. 2009. Family smoking prevention and tobacco control and federal retirement reform. Pub. L. No. 111-31, § 3(7), 123 Stat. 1776, 1782.

34 Givel M. Consent and counter-mobilization: the case of the National Smokers Alliance. $J$ Health Commun 2007;12:339-57.

35 Smith EA, Malone RE. 'We will speak as the smoker': the tobacco industry's smokers' rights groups. European J Public Health 2007;17:306-13.

36 Thomas BP, Gostin LO. Tobacco endgame strategies: challenges in ethics and law. Tob Control 2013;22(Suppl 1):i55-7.

37 Graff SK. There is no constitutional right to smoke, 2005. Available: http://www.publ ichealthlawcenter.org/sites/default/files/resources/tclc-syn-constitution-2008_0.pdf [Accessed 20 Jul 2019].

38 CPSA. 1972. Consumer product safety act. Codified at 15 U.S.C. §§ 2051-2089.

39 U.S. Department of Health and Human Services. The health consequences of smoking - 50 years of progress: A report of the Surgeon General. Atlanta, GA: U.S. Department of Health and Human Services, Centers for Disease Control and Prevention, National Center for Chronic Disease Prevention and Health Promotion, Office on Smoking and Health, 2014.

40 Suchman MC. Managing legitimacy: strategic and institutional approaches. Acad Manage Rev 1995:20:571-610.

41 Gallagher AWA, Evans-Reeves KA, Hatchard JL, et al. Tobacco industry data on illicit tobacco trade: a systematic review of existing assessments. Tob Control 2019;28:334-45.
42 Centers for Disease Control and Prevention (CDC). Quitting smoking among adults--United States, 2001-2010. MMWR Morb Mortal Wkly Rep 2011;60:1513-9.

43 Sayette MA, Wertz JM, Martin CS, et al. Effects of smoking opportunity on cue-elicited urge: a facial coding analysis. Exp Clin Psychopharmacol 2003;11:218-27.

44 Wertz JM, Sayette MA. A review of the effects of perceived drug use opportunity on self-reported urge. Exp Clin Psychopharmacol 2001;9:3-13.

45 Sharp S. Beverly hills becomes the first U.S. City to end most tobacco sales, 2019. Los Angeles Times. Available: https://www.latimes.com/local/lanow/la-me-In-beverly-hills-endstobacco-sales-20190604-story.html [Accessed 9 September 2019].

46 U.S. Food \& Drug Administration. Statement from FDA commissioner Scott Gottlieb, M.D., on pivotal public health step to dramatically reduce smoking rates by lowering nicotine in combustible cigarettes to minimally or non-addictive levels, 2018. Available: https://www.fda.gov/news-events/press-announcements/statement-fdacommissioner-scott-gottlieb-md-pivotal-public-health-step-dramatically-reducesmoking [Accessed 30 Jul 2019].

47 Craig M. Why FRR is stubbing out its tobacco habit, 2017. Available: https://www. institutionalinvestor.com/article/b1505qq3zqktkr/why-frr-is-stubbing-out-its-tobaccohabit [Accessed 25 Jan 2019].

48 Paredes-Vanheule A. BNP Paribas AM sets out roadmap for tobacco divestment, 2018 Available: https://www.investmenteurope.net/investmenteurope/news/3708312/bnpparibas-sets-roadmap-tobacco-divestment [Accessed 25 Jan 2019].

49 Fixsen R. AP4 hails financial benefit of tobacco divestment, 2018. Available: https:// www.ipe.com/countries/sweden/ap4-hails-financial-benefit-of-tobacco-divestment/ 10027822.article [Accessed 25 Jan 2019].

50 Baker S. Kempen Capital Management to divest tobacco investments, 2018. Available: https://www.pionline.com/article/20180724/ONLINE/180729937/kempen-capitalmanagement-to-divest-tobacco-investments [Accessed 25 Jan 2019].

51 Godlee F, Malone R, Timmis A, et al. Journal policy on research funded by the tobacco industry. BMJ 2013;347:f5193

52 Rabe KF, Gratziou C, Ward B, et al. Towards a total ban on links with the tobacco industry: new rules for the ERS. Eur Respir J 2012;40:809-10.

53 Park M, Selig R. San Francisco bans sales of flavored tobacco products, 2018 Available: https://www.cnn.com/2018/06/06/health/san-francisco-flavored-cigarettesproposition-e/index.html [Accessed 25 Jan., 2019].

54 Fong $\mathrm{G}$, Hammond D, Laux F, et al. The near-universal experience of regret among smokers in four countries: findings from the International tobacco control policy evaluation survey. Nicotine \& Tobacco Res. 2004;6:341-51.

55 Warren C. Brush with death: a social history of lead poisoning. Baltimore: Johns Hopkins University Press, 2000

56 Kitman JL. The secret history of lead, 2000. The Nation. Available: https://www. thenation.com/article/secret-history-lead/ [Accessed 11 Jan 2019].

57 Blakeslee S. Nicotine: Harder to kick than... heroin. New York Times, 1987. Available: http://www.nytimes.com/1987/03/29/magazine/nicotine-harder-to-kickthan-heroin. html [Accessed 6 Jun 2018]

58 Edwards R. Hardening is dead, long live softening; time to focus on reducing disparities in smoking. Tob Control 2020;29:250-1.

59 Callard CD, Thompson D, Collishaw NE. Curing the addiction to profits: A supplyside approach to phasing out tobacco. Ottawa, Canada: Canadian Centre for Policy Alternatives, 2005

60 Warner KE, Fulton GA. The economic implications of tobacco product sales in a nontobacco state. JAMA 1994:271:771-6

61 Sweanor D, Alcabes P, Drucker E. Tobacco harm reduction: how rational public policy could transform a pandemic. Int J Drug Policy 2007:18:70-4

62 Collishaw N. This should change everything: using the toxic profile of heat-not-burn products as a performance standard to phase out combustible cigarettes. Tob Control 2019;28:245-248.

63 Foulds J, Ramstrom L, Burke M. Effect of smokeless tobacco (snus) on smoking and public health in Sweden. Tob Control 2003:12:349-59.

64 Murray RP, Bailey WC, Daniels K, et al. Safety of nicotine polacrilex gum used by 3,094 participants in the Lung Health Study. Lung Health Study Research Group. Chest 1996;109:438-45.

65 Cummings KM, Morley CP, Hyland A. Failed promises of the cigarette industry and its effect on consumer misperceptions about the health risks of smoking. Tob Control 2002;11(Suppl 1):i110-7.

66 Cummings KM. A promise is a promise. Tob Control 2003;12:117-8.

67 Fracassa D. Tax for teacher salaries, ban on flavored tobacco highlight SF ballot, 2018 Available: https://www.sfchronicle.com/bayarea/article/Tax-for-teacher-salaries-banon-flavored-tobacco-12901487.php [Accessed 9 May 2018].

68 NJ bail reform a success, but needs modifications and monitoring. Press of Atlantic City, 2018. Available: https://www.pressofatlanticcity.com/opinion/editorials/nj-bailreform-a-success-but-needs-modifications-and-monitoring/article e832c73f-1f425ed2-ae45-ddfc048c0c3c.html [Accessed 9 Sep 2019].

69 Park M. California eliminates cash bail in sweeping reform, 2018. Available: https:// www.cnn.com/2018/08/28/us/bail-california-bill/index.html [Accessed 10 Dec 2018].

70 Daynard RA. Doing the unthinkable (and saving millions of lives). Tob Control 2009;18:2-3. 